\title{
I-Docs and New Narratives
}

Meaning Making in Highrise ${ }^{5}$

\author{
Begoña González-Cuesta \\ IE University, Madrid
}

Abstract: Digital media make it possible to move from a conventional storytelling medium to other avenues that allow open stories to be told, maintaining the traditional basis of narratives while also adding other elements that enrich and deepen storytelling innovation. Therefore, it is important to analyze how the characteristics of digital storytelling work together in order to create meaning through new narratives. Recent documentary projects show how new ways of telling stories involve new ways of relating meaning and form, multiple platforms, and strong interaction and engagement from the side of the viewer. Interactivity and participation change the way in which a story is told and received, thus changing its nature as a narrative. In order to delve deeper into this field, I will analyze Highrise. The Towers in the World. World in the Towers, (http://highrise.nfb.ca) by Katerina Cizek. This is a complex project produced by the National FilmBoard of Canada, a multiyear, many-media collaborative documentary experiment that has generated many projects, including mixed media, interactive documentaries, mobile productions, live presentations, installations and films. I will develop a textual analysis on the part of the project, the interactive documentary Out My Window, by focusing on its ways of meaning-making and the specific narrative implications of the relationship between meaning and form. The project is ambitious: Cizek's vision is “to see how the documentary process can drive

5. Article first published by \#IFM2014 Conference: Moura, Hudson et al. (eds.). Interactive Narratives, New Media \& Social Engagement International Conference Proceedings. Reprinted with Author's Permission. 
and participate in social innovation rather than just to document it, and to help reinvent what itmeans to be an urban species in the $21^{\text {st }}$ century."

\section{Introduction \\ Digital media, audiovisual narratives, anddocumentaries}

The "call for papers" of this conference brings into focus the need to reflect on interactivenarratives and digital media, especially on the ways in which individuals and societies represent themselves on these screens and the ways these representations deal with their identities at a creative, social and political level in a globalized context.

These days, two elements of our communication ecosystem converge: the growing interest in non-fiction digital narratives from both creators and consumers and the enormous impact digital media has on the way stories are told and received. In most of the cases of digital media narrations, the traditional basis of storytelling remains, but new elements are added into the mix, such as interactivity, use of multiple media, the transmedia dimension in some cases, etc.

This new environment, the digital media ecosystem, allows creators to develop innovative ways to represent reality innovations that, in some cases, have to do with a deeper and richer approach to the topics. Digital media make it possible to move from a conventional storytelling medium to other avenues that allow open stories to be told, maintaining the basics of narratives while also including other aspects that enrich and deepen 
storytelling innovation.

Some of the questions that arise in this context include the following: What is the process, and what are the consequences of meaning-making in digital narratives? Does it have to do with a different way of relating meaning and form? Is it connected to the use of multiple platforms? In what ways? Does it allow a strong interaction and engagement from the side of the viewer? Is interactivitychanging the way a story is told and received, therefore changing its nature as a narrative? Does it generate a different notion of authorship? What are the consequences in terms of meaningmaking? In brief, digital media aregiving us great opportunities to rethink the notion of narrative.

Moving more specifically into interactive documentaries or web documentaries, it is important not to forget that the bases of documentary creation remain and are still present in new projects, but taking different shapes, as expressed here:

The documentary impulse has a long history; practitioners are, it seems, still driven to preserve, show, report, explain,persuade and advocate. But it is also an impulse that is constantly seeking new avenues, new ways of capturing the social-historical, or 'treating' actualityand new ways of connecting with an audience. [...] Documentary has always had an experimental dimension with first filmmakers, and now digital documentary makers adopting and adapting emerging technologies and generating new documentary forms. (Nash, Hight, \& Summerhayes, 2014, 1)

Innovation is one of the keywords related to this kind of

documentary. And it is especially significant in the way meaning is created in interactive documentaries. Sandra Gaudenzi(2014) says: 
While in linear documentaries meaning was created by framing shots and editing them together, in participatory interactive documentaries meaning is shared and layered: there is the meaning of the individual clips (not controlled by the interactive documentary author), the meaning of the interface (normally conceived by the author) and the meaning of the browsing (the narrative route and associations generated by the user, while jumps between videos). The challenge, therefore, lies in playing with those layers to create a richer meaning, while avoiding the trap of internal contradictions." ( 138)

\section{Highrise and Out My Window: a briefdescription}

Along these lines, I decided to analyze a very interesting project, Highrise, by Katerina Cizek. I consider this work extremely stimulating for the following reasons: it explores new ways of telling stories in an interactive, digital and collaborative way; it deepens into the life at the margins, exploring how human life in these spaces is richer than some stereotypes could suggest; and all this is done by exploring new ways of searching for meaning, thinking about some dimensions of reality, and doing it by creating audiovisual works in which the most radical relationship between content and form is essential.

I will start by describing this work and its context. Highrise is a documentary project directed by Katerina Cizek at the National Film Board of Canada. In fact, it's a multi-year, many media collaborative documentary experiment that has generated many projects, including mixed media, interactive documentaries, mobile productions, live presentations, installations, and films. All these experimental projects are available on a common website: http://highrise.nfb.ca. Each sub-project has a meaning of its own and can be experienced independently from the others, but all 
together,they form a rich, diverse, complex, and orchestrated approach to vertical living in the contemporary world. All of them approach a common topic: what is human life like in residential highrise buildings.

Highrise was launched in 2009 and now includes the following projects: The Thousandth Tower, Out My Window, One-Millionth Tower, A Short History of the Highrise (in partnership with The New York Times), and the director's blog.

I will focus my analysis on the web documentary Out My Window, produced in 2010. It also took the form of an interactive exhibition. The previous and first project, The Thousandth Tower, was focused on the city of Toronto. In this second project, Cizek wanted to explore vertical living around the world. Shedidn't want to approach life in big cities, famous for their highrise buildings such as New York, Tokyo or Paris, but decided to look into the medium cities and their suburbs. Using social media, she found 13 subjects in different countries in the world interested in sharing their experiences and lives throughthis digital documentary. The work was shot inChicago, Toronto, Montreal, Havana, SaoPaulo, Amsterdam, Prague, Istanbul, Beirut,Bangalore, Phnom Penh, Tainan, and Johannesburg.

Out My Window received the inaugural IDFA DocLab Award for Digital Storytelling. In April 2011, it was awarded the International Digital Emmy Award in the category of the digital program: non-fiction. In April 2011, the web documentary was nominated for a WebbyAward for Best Use of Photography in the Websites category. On May 10, 2011, Out My 
Window received the New Media Award at theOne World Media Awards.

This is a snapshot of the main interface of Out My Window (see Fig. 1).

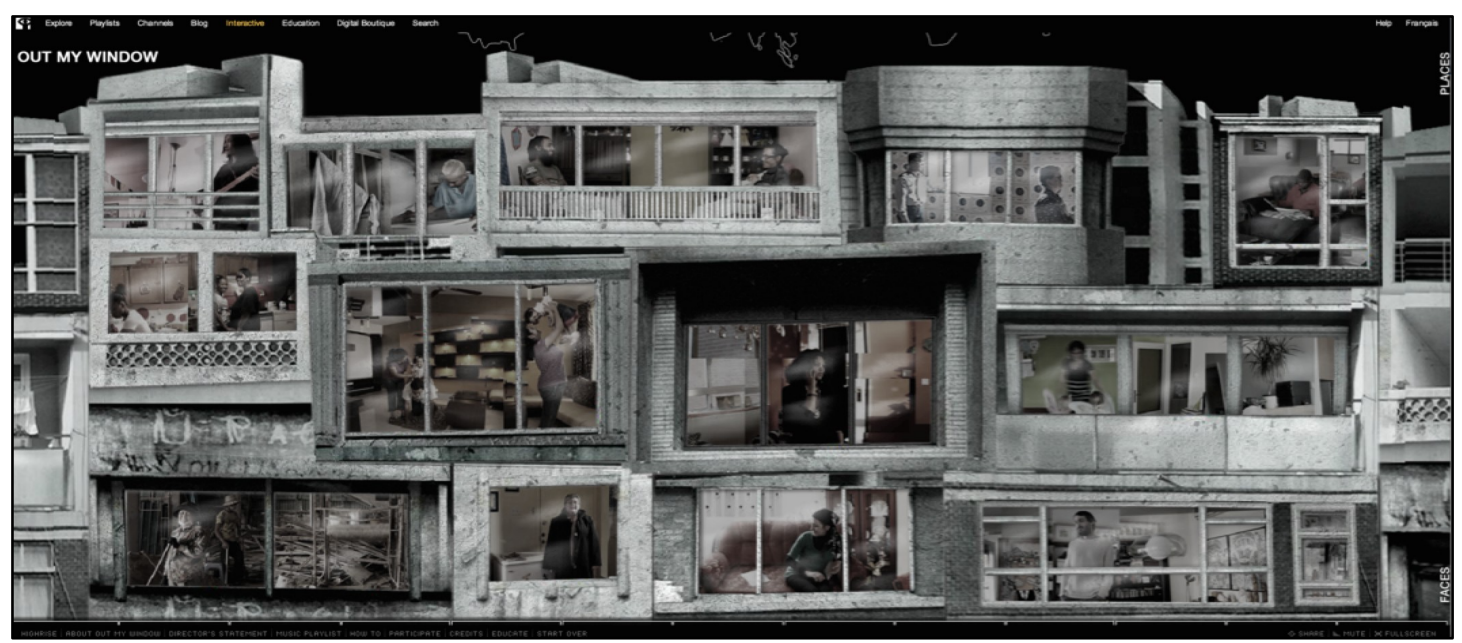

Fig. 1: A snapshot of the main interface of Out My Window.

The work is described on the website as follows:

One Highrise. Every view a different city.This is Out My Window-one of the world's first interactive $360^{\circ}$ documentaries-about exploring thestate of our urban planet told by people who look out on the world from highrise windows.

It's a journey around the globe through the most commonly built form ofthe last century: the concrete-slabresidential tower. Meet remarkable highrise residents who harness the human spirit and the power of community toresurrect meaning amid the ruins ofmodernism.

With more than 90 minutes of material to explore, Out My Window features 49 stories from 13 cities, told in 13 languages, accompanied by a leading-edgemusic playlist. (OMWWebsite, http://interactive.nfb.ca/) 


\section{Representation, meaning-making and marginal realities}

The most relevant questions raised by Highrise have to do with the concept of representation and its consequences on meaning-making, in this case about marginal realities. The project raises some questions that directlytouch on one of the most relevant aspects of our contemporary cultures.

I will now develop some ideas about what audiovisual works can do in today's media ecosystem to understand human life byrepresenting in a particular way marginal realities with the goal of thinking about them and having a real impact on individuals and societies. Afterwards, I will go into some details of Cizek's conception of the documentary, relatingthese general ideas to the reflections and objectives she has expressed as being thebasis of her creative endeavour.

A crucial issue nowadays is the role of images in the construction of our worldview. Inthis paper, I am taking into consideration a topic that has to be confronted, both from the academic and from the creative world. In orderto build our present and our future as citizens involved in the creation of our culture, we needto think about reality as something that we"imagine" in the most radical sense of the word: reality as something that somehow is built when images about it are created. And I think we have to make a joint reflection between academics and creators, putting together and crossing these two possible approaches to the complex and fascinating factof generating images of reality in order to thinkabout it. 
The audiovisual media are increasingly influencing our contemporary society; this is one of the key ideas that lies at the heart of the reflection raised by this conference. Language allows us to know and understand the world, creating culture, and the language ofthe $21^{\text {st }}$ century is audiovisual, digital and multimedia. The way we communicate, think, and build our representations of reality involves the creation of audiovisual and digital works. It is therefore essential to know in depth the language and the culture that is generated to learn how to read and write these images.

In a changing and complex world suchas ours, it is necessary to know how to think, analyze, address reality in multiple dimensions, and understand and manage the languages, including visual language. Going deeper into the visual language, our understanding of reality will grow, and, therefore, our skills for analysis, interaction, flexibility, creativity, aesthetic awareness, engagement, and critical thinking will be developed. We are not just in possession of some new tools, but those tools are generating new languages, new messages, new ways to receive those messages, and new forms of influence.

In this context, a discussion about the consistency of these visual representations of reality is necessary. We face the long-standing dichotomy: Is the image a means for knowledge or a sham that anesthetizes our senses? We have to approach the forms of representation of reality critically. Obviously, we are far from believing that realism is like that image of the "mirror that strolls along the way." We know about the need for 
"building visual elements" so that realism becomes significant. Thus, it appears necessary to stop and think about the images and focus on the images that "think."

It is necessary to reflect on the ways of developing deep thoughts in contemporary art. Jean-Luc Godard coined-and often used torefer to the cinema-the expression "a form that thinks." Any form of art can be a device that serves as a means for thought. I am suggesting an approach to contemporary poetics in different areas of creation, conceived as ways in which thought is materialized, therefore considering artistic work as an epistemological and hermeneutic way to create meaning. The best contemporary art is set up as a place for re-creation of the sense ofreality, as a gateway to the real in-depth.

Our analytic perspective, therefore, focuses on studying the audiovisual creations in which the search for meaning is in their heart. In this regard, it is crucial to note that the reflective audiovisual thinks through its ownmaterials; it doesn't illustrate with images a previously constructed thought. The audiovisual thought generates a reflective process in the images and the sounds; the hermeneuticaldimension lies in the heart of the work(González Cuesta, 2006).

To consider the image as a window to the world, as a place of transparency, would be an extremely naïve conception. From the parameters of contemporary thought, we consider more appropriate an approach to the image from a certain opacity: the image is not a space of 
safe transition to a reality which is given us to see, and no more. We have tostop in front of the image and, looking closely, we will find its meanings, with an in-depth approach to the real. I refer to this in regard to a reflection by Josep Maria Català on "thecomplex image," the image conceived as aspace in which reality is revealed phenomenologically and hermeneutically deepened its meaning-an image that builds knowledge, that leaves behind the "epistemology of reflection" to address the "epistemology of inquiry:"

The 'complex image' breaks the mimetic link that images traditionally had with reality and replaces it with a hermeneutical link: instead of an epistemology of reflection, an epistemology of inquiry is proposed. Images no longer passively reflect the real but go after it [...] It doesn't mean that images are a simpletool to build the real but indicates that reality, in order to be really significant, must be uncovered and that the complex visualization is an effective way to do it. (Català, 2005, 642-43)

It is, therefore, necessary to analyze creative thinking in audiovisual work. The real image that seeks to be a creative-thinkingimage does not merely reflect reality as if it were a mirror image. As Català says, to show something is not necessarily to help to understand that reality. In order to make meaning out of the images, something has to be done:

It is not about producing a copy of reality, neither about showing what remains after the surrender of copying it, but to reveal through the visible a hiddendimension of reality: in the paintings of Bacon, the world is reborn throughforms. (Català, 2005, 37)

One of the most important debates today is about the role of images in theconstruction of our world. In a context in which the saturation of images is growing, we can reach the paradoxical situation in which images don't let us see, don't let us look intowhat we need to know. In the era of 
proliferation of television channels, mobile phones andscreens to access any image, in the world of YouTube, of security cameras that record everything, of the desire to transform into banal images any facet of existence, of teenagers recording the beatings they give to their school mates to have a moment of "glory" on the Internet, of the time when we seem to get used to seeing landscapes of desolation and broken bodies by violence-it is necessary to consider this issue. The most complex dimensions of reality are often left without a representation that addresses its complexity.

Such images, rather than making meaning about reality, deny visibility to deeper realities. We should reflect on the ethics of the missing images. Against this, the creative images can be effective tools to fostera dialogue on these realities beyond the monologue generated by the mass media; creative realities can critically challenge thehegemonic and dominant images.

Nowadays, new modes of realism in image creation are emerging, involving new ways of engaging with reality. Following the issues raised by Ángel Quintana (2003), beyond the easy and sentimental speeches, beyond the "shy realism" that works only on the mimetic dimension of images, some works address a "strong realism" or "critical realism,"the construction of an ethical perspective on the issues in need of it.

In short, I consider necessary the study of contemporary imagethoughts that work on margins. It is about knowing how to formally construct these image-thoughts and why togenerate reflections on those 
marginal situations. It is important to address one of thegreat debates in our culture: the role of images as a cultural construction. Sometimesthe more complex layers of reality are left out-of-frame, relegated as nonexistent by the media. It is more and more necessary to reflect on the representation of margins. We need to think about what realities are left aside by the hegemonic representations, what marginalrealities are addressed by the image-thoughts and how they are constructed to provide support for reflection, and finally, how image thought is a way of critically challenging the status quo. There's a need to consider theethics and poetics of the representations of the conflicts generated in the margins of reality.

The margins, the borders, the thresholds, the limits have to be addressed. The framework of the concept of "border" or "limit" in our analysis rests on a philosophical foundation, a theoretical basis that I consider extremely firm yet disturbing: the philosophy ofthe limit of the great Spanish philosopher Eugenio Trías, especially and essentially his conception of humans as beings that live on the border, and his understanding of creation as a symbolic space where the richer ways of living takes place on the frontier. Particularly relevant is his work Los límites del mundo, (1985, Barcelona: Destino).

\section{Reflections about representation, meaning making and marginal realities regarding Out My Window}

I already said that the most relevant questionsraised by Highrise have 
to do with the conceptof representation and its consequences on meaning making, in this case, about marginal realities. And it is also important to underline the idea that this project touches on some of the most relevant aspects of our contemporary cultures: representation, search for meaning, margins.

The main interface of Out My Window could work as a perfect metaphor for the ideasl have been developing so far. By approachinga twodimensional representation of a building, we can go further and enter into a whole and diverse life that is behind. The interface works as the threshold through which reality inits complexity can be reached. "On the outside, they all look the same. But inside these towers of concrete and glass, people create community, art and meaning" (OMW website).

This is how it works if we think about thisproject from our perspective, the users' point of view. But, at the same time, and maybe more importantly, by designing this interface, Cizek is placing the focus on the other side: the eyes of the inhabitants of those spaces. Their homes "are represented," and they lookat the world from those spaces. "What do people see out their own windows? I didn't want tojust look into people's homes; I wanted to work with residents to see their experiences from their point of view. Their windows onto the world" (OMW website). The interactive dimension of this work helps to mirror the different points of view when approaching how lifeis at the highrise buildings around the world. 
An important source for understanding the reach and depth of this project can befound in the texts created by Cizek and presented on the website of Highrise, and more specifically, on the website of Out My Window. The explanations developed by Cizek on the website reveal the broad scope of the theory of documentary implied in Out My Window. Some of the general ideas I expressed about contemporary audiovisual creation relate to the reflections and objectives expressed byCizek as being the basis of her creative enterprise.

"The idea was simple: to build a virtual highrise, with each floor housing a differentglobal city. But the process behind the idea was a fusion of many conversations I had been having with our technological, creative and editorial teams," says Cizek on the website about the interface design. And the way toexpress this idea touches upon another relevant aspect of this work: the intention of having conversations with different groups in order to develop a deep reflection about this reality. Conversations were held at many different levels and collectives: conversations with the people living in the highrise buildings, academic conversations, conversations about the documentary, and conversations with the new media world.

The participatory aspect lies at the core of this work. And, at the same time, Cizekmaintains the idea of coordinating theconstruction of this text, of orchestrating the conversation. Many different options can be taken regarding authorship in interactive documentaries. In this case, as Sandra Gaudenzi explains after interviewing Cizek: 
The material is not even user generated,it is subject generated. When I askedKaterina Cizek her views on UGC she replied 'I am not interested in UGC, Iwant to maintain an authorial role'. Sheis the facilitator, and as such she maintains the authorship of navigation, whichshe considers as a type of content. What she opens to collaboration is the voice given to the subject. She accepts subjectproducers. (Gaudenzi 2014, 141)

There is an ethical perspective in understanding participation and authorship in thisway. As Craig Hight says about interactive documentaries: "Editing, in other words, is not simply about representing a reality, but actively interpreting it for an audience (Oldham 1992,133), and thus is also at the coreof the ethical dilemma inherent to documentary practice (Cizek 2005, 174-78)." (Hight, 2014, 223).

In the description of this work, we can find the following statement: "Meet remarkablehighrise residents who harness the human spirit-and the power of community-to resurrect meaning amid the ruins of modernism" (OMW website). It seems that for her, the bestway to find the meaning of human life and the sense of living in a community amid today's confusion is to approach real stories of peopleliving their lives in an actual search for meaning. Cizek's vision is "to see how the documentary process can drive and participate in social innovation rather than just to document it, and to help reinvent what it means to be anurban species in the $21^{\text {st }}$ century." The goal is ambitious, but it is in line with the best documentary tradition, envisioning the representation of reality as a way to understand and change the world.

In this case, the focus of attention is placed on a growing model of 
living: "It's a new species of urban. The world's cities are actually growing fastest at their edges. At the fringes. The margins. The suburbs" (OMW website). And it is explicitly mentioned on the website that this phenomenon is overlookedby politicians and the media. And for Cizek, our eyes have to turn to look into those marginal spaces because they are not thatmarginal for understanding contemporary societies and because some of the most interesting things are happening there:

[...] in order to understand urbanization-and that means to understand the planet because we are now living on an urban planet-we need to understand the peripheries, the edges of our cities, and that's where the most exciting, problematic, complicated things are happening. Yet we really have no clue about how these places work, both culturally, politically, economically, at all levels. (CollabDocs)

One of the main objectives of the projectis to challenge our perceptions of urban experience. Cizek explains:

It also made me rethink where urban 'culture and politics' reside. My naïve understanding of suburbs-a retreat for the middle classes-was a simplistic, outdated stereotype. The urban peripheries both horizontal and vertical are places overflowing with humanity, yet are often invisible to the drive-byeye, to the closed mind. (OMW website)

I pointed out how crucial for making a thoughtful representation it is to work together on the formal and content aspects of a project.By doing that, representation moves from being a mirror of reality to being a light that makes clearer and deeper what we are looking into. In that respect, Cizek's statement,"Out My Window is a documentary that findsits form from the content and vice versa," is especially meaningful. It was important to find the best way to tell how life is in the highrise buildings around the 
world:

The fragmented, non-linear stories of Out My Window reflect the way we tellour stories. Pieces. Snippets. Small tales that, as they add up, create a collage of meaning, of experience. Together, subtly, gently, the stories accumulate into epic narratives aboutglobalization, migration, poverty, environmentalism, reclamation, and the search for spiritual meaning. But only ifyou search between the seams, andsew it together for yourself as you listen. [...]. We would create collages, overlappings, doublings. Many seams. Leaving room for interpretation, for the unspoken, the unsaid, the private, the personal. (OMW website).

To conclude, I will reproduce here this sentence by Katerina Cizek that perfectly summarizes the spirit of Out My Window:

To be human in this century is - more than ever before-to be urban. And yet, we have such a meagre understanding of what that really signifies. It is not about the financial capital in the downtown core. It is to our peripheries that we mustlook for the neglected pressing needs of the most vulnerable, for stark economic injustices, for the inspiration to change, and for the search for meaning amid the concrete. (OMW website). 


\section{Bibliography}

Català, J. M. La imagen compleja, Barcelona: Universitat Autónoma de Barcelona, 2005.

CollabDocs Interview to Katerina Cizek, 2014. URL:

http://collabdocs.wordpress.com/interviewsresources/katcizekonhig hrise/

Gaudenzi, Sandra. "Strategies of Participation: The who, What and When of Collaborative Documentaries," In Nass, Kate, Hightt, Craig and Summerhayes, Catherine (eds.). New Documentary Ecologies (Emerging Platforms, Practices and Discourses). Palgrave Macmillan, 2014.

González-Cuesta, Begoña. (2006). "El cine como forma que piensa: La Morte Rouge de Víctor Erice”, Oppidum. Cuadernos de investigación, $\mathrm{n}^{\circ} 2$ 2, (2006): 187-214.

Hight, Craig. "Shoot, Edit, Share: Cultural Software andUser Generated Documentary Practice," In Nass, Kate, Hightt, Craig and Summerhayes, Catherine (eds.) New Documentary Ecologies (Emerging Platforms, Practices and Discourses). Palgrave Macmillan, 2014.

Nass, Kate, Hightt, Craig and Summerhayes, Catherine(eds.) New Documentary Ecologies (Emerging Platforms, Practices and Discourses). Palgrave Macmillan, 2014.

Quintana, A. Fábulas de lo visible. El cinecomo creador de realidades, Barcelona: El Acantilado, 2003.

Trias, E. Los límites del mundo, Barcelona:Destino, 1985. 